\title{
Wear of PM HIP Metal Matrix Composites - Influence of Carbide Type
}

\author{
Tomas Berglund $^{1, a_{\star}}$, Josefine Hall ${ }^{2, b}$ \\ ${ }^{1}$ Sandvik Powder Solutions, PO Box 54, 79521 Surahammar, Sweden \\ ${ }^{2}$ Dalarna University, 79188 Falun, Sweden \\ atomas.berglund@sandvik.com, bjoh@du.se
}

Keywords: HIP, Wear, Tribology, Metal Matrix Composites, MMC, Wear Resistant

\begin{abstract}
The type of hard phase in combination with matrix material has a great influence on the wear properties of PM HIP Metal Matrix Composites. The hardness and toughness of the hard phase as well as its reaction with the matrix in combination with wear mechanism can cause significant differences in performance of the material. Three materials with the same matrix alloy but different carbide types have been studied with regards to tribological behavior in low stress and high stress abrasion as well as scratch testing against a quartz stylus.

In low stress abrasion testing the materials has only very small differences in the performance between the materials. The materials containing crushed or spherical fused tungsten carbide had a higher initial wear rate compared to the material with macrocrystalline carbide. This can be explained by the higher degree of carbide dissolution in these materials. In the later stages of wear the three materials have similar performance. In the scratch testing a clear difference can be observed between the materials. The material containing the fused tungsten carbide exhibits a higher degree of carbide damage at the exit side of the wear scar sliding over the carbide. This can be attributed to the much higher degree of carbide dissolution in the fused carbide compared to the MC carbide. The results from tribology testing are discussed and compared to wear mechanisms observed in parts that have been in service in a slurry pump and a crusher.
\end{abstract}

\section{Introduction}

Wear-resistant materials are important in several industrial processes including manufacturing, energy production, construction and mining tools or in nuclear, aerospace and gas turbine industry [1-6]. Wear resistant metal matrix composites are composed of hard particles like carbides, borides and nitrides embedded in a ductile metal matrix of for example Co, $\mathrm{Ni}$ and/or Fe [2-5]. These two components serve different purposes. The hard particles need to impede abrasive wear by grooving or indenting hard particles while the metallic matrix should provide toughness. The properties of the composite material depend on both the chemistry of each component as well as the size and amount of the hard particles.

Wear resistant composites with tungsten carbide hard phase is commonly used as an overlay material in e.g. the mining industry. The overlay process used to apply these materials on to a part e.g. Plasma Transfer Arc Welding have limitations with regards to e.g. chemistry, hard phase size, overlay thickness etc. The use of Hot Isostatic Pressing provides an attractive alternative to these processes as it offers more freedom in the composition of the material and the wear resistant material can be applied to surfaces at an unlimited thickness.

The type and shape of tungsten carbide will affect the properties of the material. The fused tungsten carbides consisting of an approximate $80 / 20 \%$ mix of the $\mathrm{W}_{2} \mathrm{C}$ and WC phase respectively has a higher hardness than Macro Crystalline WC. However, the benefit of the MC 
carbide is that it resists dissolution during consolidation much better than the fused carbide, in which the $\mathrm{W}_{2} \mathrm{C}$ phase is more prone to dissolution [7]. The dissolution can affect the wear resistance of the material [8, 9]. Furthermore. the different tungsten carbide types have different mechanical properties that also affect the tribological behavior of the materials.

The effect of carbide type and morphology on the wear resistance of HIPed metal matrix composites were investigated using high and low stress abrasion testing as well as scratch testing. The resulting wear scars were investigated using SEM/EDS. The wear mechanisms found are discussed with respect to the microstructure and material properties.

\section{Experimental}

Materials. The materials were produced at Sandvik Powder Solutions in Sweden using Hot Isostatic Pressing (HIP). The matrix and tungsten carbide powders were weighed and mixed to achieve a 50 vol.\% carbide content in the material. The powders were mixed in V-blender for 3 hours. A NiCrSiBC alloy was used as matrix for all materials. The mixed powder were filled in to a capsule $(180 \times 70 \times 50 \mathrm{~mm})$ which was then evacuated and HIP:ed at $100 \mathrm{MPa}$ and $1150^{\circ} \mathrm{C}$ with 2 hour dwell time. Three materials; with crushed fused tungsten carbide (80/20 mix of $\mathrm{W}_{2} \mathrm{C}$ and WC) (F50), spherical fused tungsten carbide (FSP50) and MC WC (MC) (F50MC) respectively. The carbide particle size used was $100-300 \mu \mathrm{m}$. The same for all the materials although the particle size distribution vary slightly. From the HIPed specimens the samples were cut using Electric Discharge Machining.

Samples used in scratch testing were polished to $1 \mu \mathrm{m}$ using diamond emulsion in the final step and were cleaned in acetone, water and ethanol before scratch testing. For abrasion testing the specimens were ground to remove white layer from EDM and to produce a controlled surface before testing. Resulting surface finish was approximately Ra 0,6 $\mu \mathrm{m}$.

Abrasion testing. Low stress abrasion testing was performed using a modified version of procedure ASTM G65 A. When testing highly abrasion resistant materials it has been found that normally used one or two passes (see table 1 for test parameters per pass) is not enough to characterize the wear resistance of the material. This because after two passes the material removed in testing is only matrix material between the hard phase particles. Instead the testing has been made in 6 passes with weight loss measurement after each pass. The measured average weight loss $(0,001 \mathrm{~g}$ precision) for three tests was then used to calculate volume loss.

High stress abrasion was carried out with the testing parameters seen in table 1 . Average weight $(0,01 \mathrm{~g}$ precision) loss of three tests was used $(0,01 \mathrm{~g}$ precision). The basics of the test is described in standard ASTM B611 where it is also mentioned that it is the preferred test method for testing of cemented carbides.

Hardness testing. Hardness testing was performed using a CSM Micro Combi Tester for micro hardness measurement. Load was $200 \mathrm{~g}$ for carbide

Table 1. Test parameters for low and high stress abrasion testing.

\begin{tabular}{|l|l|l|}
\hline & Low stress & High stress \\
\hline \hline Base procedure & ASTM G65 A mod. & ASTM B611 \\
Abrasive media & Silica sand \#50-70 & $30 \#$ Al2O3 \\
HV abrasive & $1100 \mathrm{HV}$ & $2200 \mathrm{HV}$ \\
$\begin{array}{l}\text { Slurry } \\
\text { Wheel material }\end{array}$ & R/A & $80 \%$ abrasive 20\% H20 \\
$\begin{array}{l}\text { Wheel RPM } \\
\text { Sand flow rate }\end{array}$ & 212 & AISI 1020 Steel \\
$\begin{array}{l}\text { Force } \\
\text { No revolutions }\end{array}$ & $1300 \mathrm{~N}$ & $100 \pm 5 \mathrm{rpm}$ \\
Sliding distance & 4309 meters & $518-530$ meter \\
\hline
\end{tabular}

hardness and $25 \mathrm{~g}$ for matrix hardness. For macro hardness, HRC testing was performed in a 
Leco RT-240 hardness tester. The average was calculated from five tests. In hardness testing of carbides and matrix, indentations that caused significant cracking of the carbide or that contacted underling carbides (severe indent distortion) was excluded. Imprints on carbides were made on carbide particles that was at least ten times bigger than the imprint diagonal.

Scratch testing. A conventional scratch tester CSM Revetest ${ }^{\circledR}$ was used for scratching the sample surfaces. The stylus used was a pyramidal quartz $\left(\mathrm{SiO}_{2}\right)$ stylus. In the quartz scratch test the scratch length was $5 \mathrm{~mm}$ at the speed $10 \mathrm{~mm} / \mathrm{min}$ at the load $50 \mathrm{~N}$.

\section{Results}

Microstructural characteristics. The microstructure of the three materials is shown in Fig. 1. The F50MC material exhibits a very low amount carbide dissolution as well as a high degree of fracturing in these carbides. It is also evident that the angular eutectic carbide has a slightly higher degree of dissolution compared to the spherical. This is due to the slightly higher amount of the more dissolution prone $\mathrm{W}_{2} \mathrm{C}$ phase in the angular carbide as well as a higher surface area and coarser structure of the angular carbide. Left behind are needle shaped WC-phase extending out in to the matrix as well as smaller secondary precipitates in the matrix between the primary carbides. This dissolution increases the mean free path between the larger primary carbide particles that contributes mostly to the wear resistance of the material by resisting damage caused by abrasive particles. This can have a negative effect on the wear resistance of the material as the matrix between the primary carbides is more accessible to wear. The dissolution of the spherical carbide is much lower and a three-layer structure has formed in the carbide. A $2 \mu \mathrm{m}$ layer of what is believed to be MC carbide, a 10-15 $\mu \mathrm{m}$ transition zone 2-phase WC/W2C structure but that has coarsened slightly and in the center the original structure of the spherical carbide.

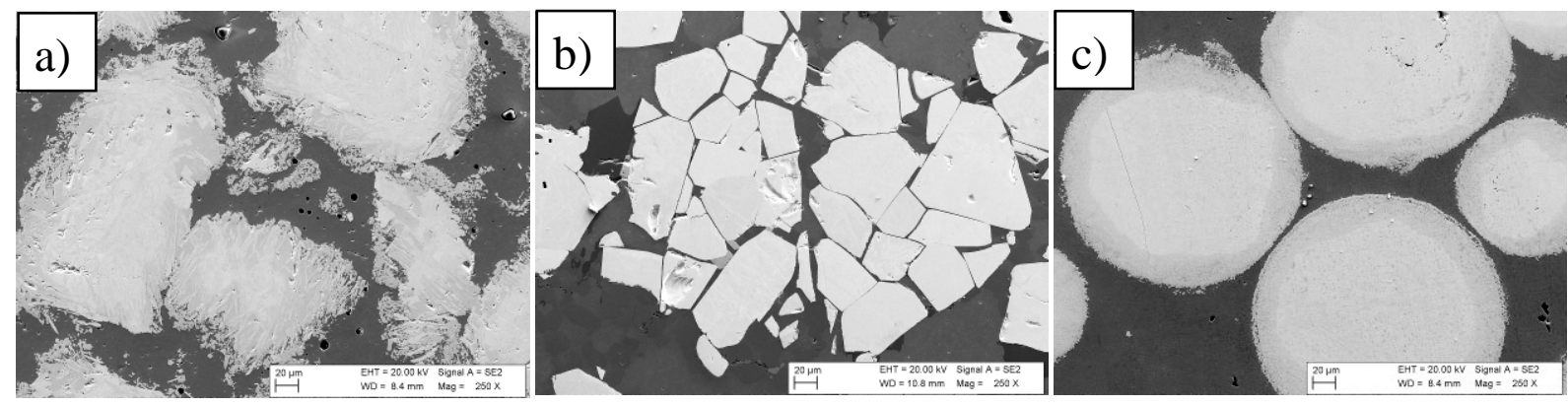

Figure 1. Microstructure of F50 (a), MC50 (b) and FSP50 (c).

Mechanical characteristics. The macro hardness of the materials as well as micro hardness of the matrix and carbides can be seen in figure 2 . As can be seen the spherical eutectic carbide have the highest hardness followed by the fused crushed carbides and the macro crystalline carbide. A higher amount of carbide dissolution have increased the hardness of the matrix by solid solution strengthening by $\mathrm{C}$ and $\mathrm{W}$ but also precipitating small carbides in the matrix.

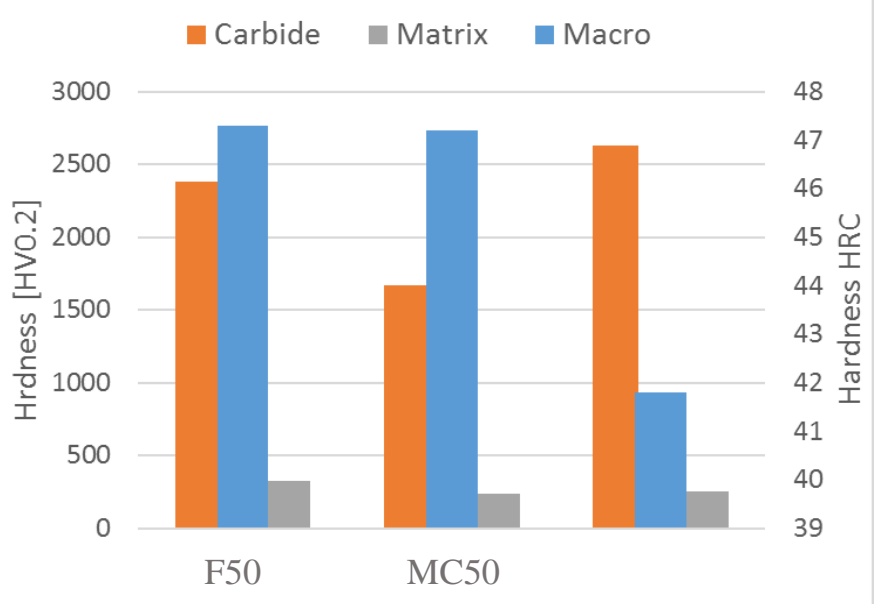

Figure 2. Macro hardness of material and micro hardness of carbides and matrix. 
Tribological characteristics. Figure 3 show the volume loss per pass and cumulative volume loss in low stress abrasion testing. It is evident that the F50MC material has a slightly lower initial wear compared to F50 and FSP50. This can be attributed to the lower degree of carbide dissolution in this material (see figure 1). Higher degree of carbide dissolution as in F50 increases the mean free path between the primary carbides causing abrading sand particles to more easily remove the softer matrix material along with the small carbides between the primary carbides. The higher degree of carbide fracturing during HIP in F50MC further lowers the mean

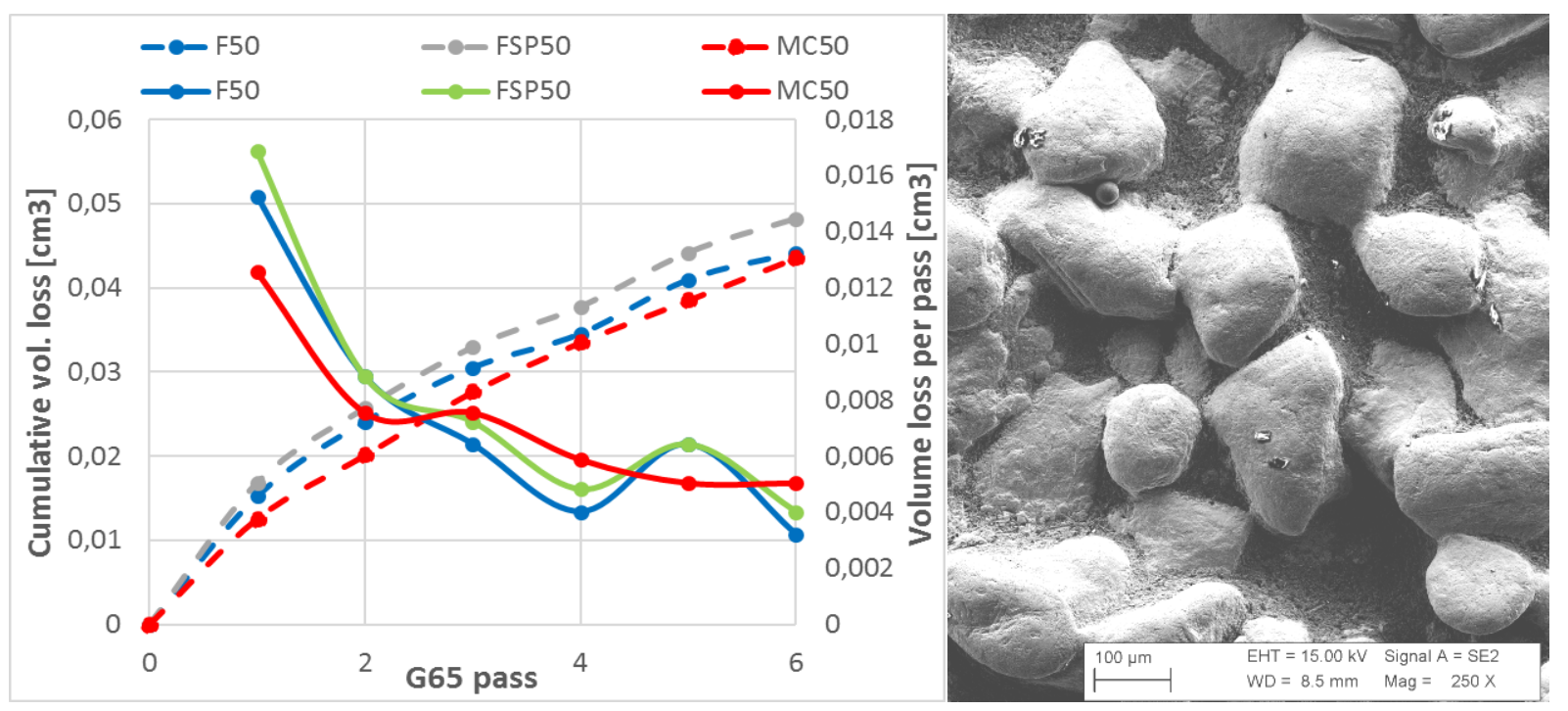

Figure 3. Cumulative and volume loss per pass in $\mathrm{cm}^{3}$ in ASTM G65 testing and to the right the worn surface of F50 after $6^{\text {th }}$ pass of testing.

free path between the primary carbides, but also reduce their effective size. The FSP50 material with spherical particles peı carbide particles combined with a size distribution towards the larger end increasing mean free path.

After the initial stage (pass 4) of wear, it's mostly matrix material that is being worn away, there is very little difference between the materials, and wear rate starts to stabilize. The hardness of the abrading particles is significantly lower than all the carbides. This in combination with the low contact pressure used results in that the carbides resists wear quite well. In fact, the material with the lowest hardness perform the best, although mainly due to better performance in the pass one and two. This indicates that during low stress abrasion the major controlling property is not hardness but rather mean free path of the carbides, the wear resistance of the matrix as well as the carbide-matrix bond strength. The controlling factor in the wear process is the removal of the matrix material between the carbides. When a sufficient amount of matrix is worn away, the carbide particles

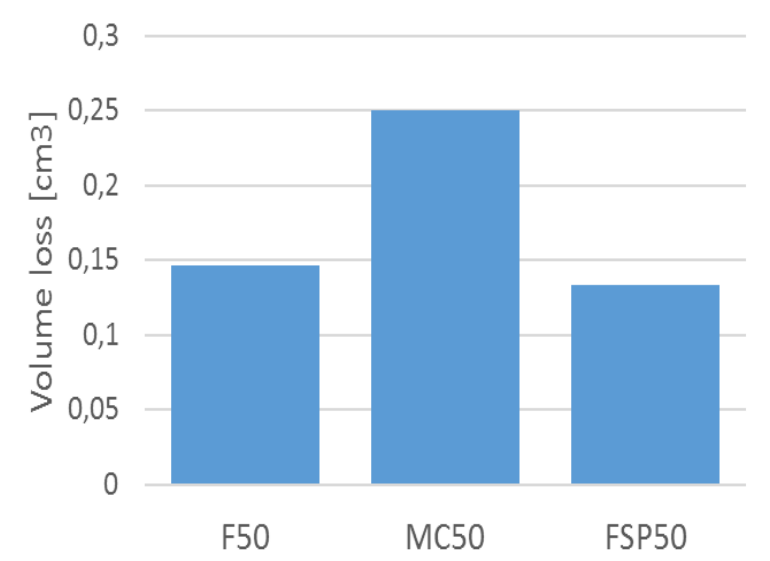

Figure 4. Average volume loss in high stress abrasion testing after 1000 revolutions. 
lose their support from the matrix and can readily be removed as wear progresses. As can be seen in figure 3 the wear rate in the material does not start to stabilize until the $4^{\text {th }}$ to $6^{\text {th }}$ pass of testing. Even at this stage the total depth of the wear scar is still quite low relative to the carbide size and the majority of the wear has occurred in the matrix between the carbide particles, see figure 3.

Figure 4 shows the average vol. loss in high stress abrasion testing. The harder angular abrasive particles in combination with a higher load and the harder counter surface leads to much more severe wear conditions and significantly higher vol. loss. In this test the abrasive particles generally fracture during the test and other studies have shown that the fractured particles tend to produce even greater wear than the originally added particles [10].

A clear correlation can be found between carbide hardness and wear resistance of the materials. It is evident that the softer MC carbide in the F50 MC material results in a lower wear resistance in this test. It has been shown in other studies [11] that the abrasive wear rate drops drastically when a materials hardness goes above $80 \%$ of the abrading particles. For the low stress abrasion testing the hardness of the carbides for all the materials are more than twice that of the abrading particles. However, for the $\mathrm{Al}_{2} \mathrm{O}_{3}$ particles used in the high stress abrasion testing the hardness of macro

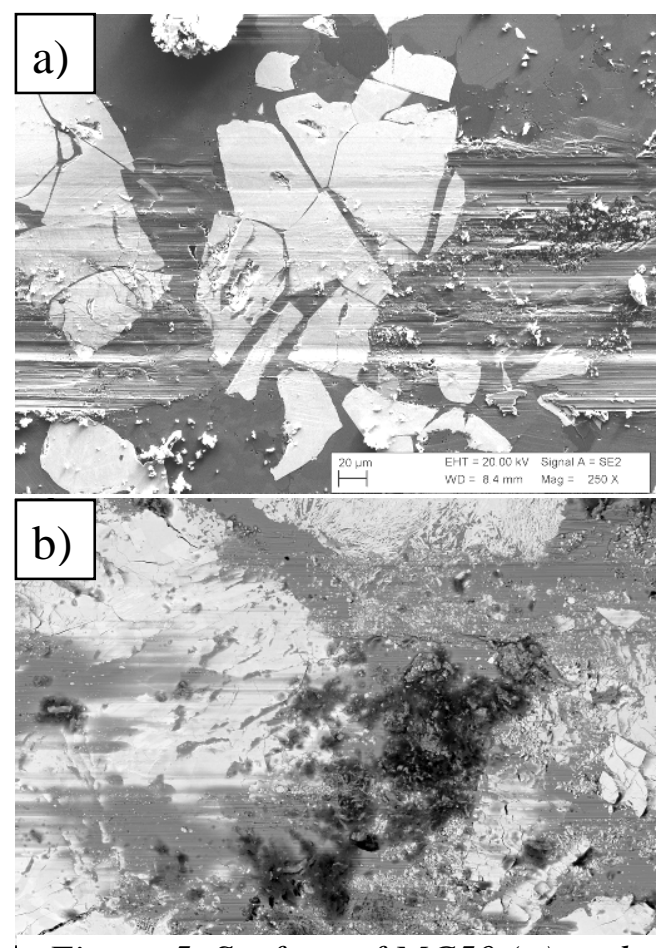

Figure 5. Surface of MC50 (a) and F50 (b) after scratch testina aqainst a
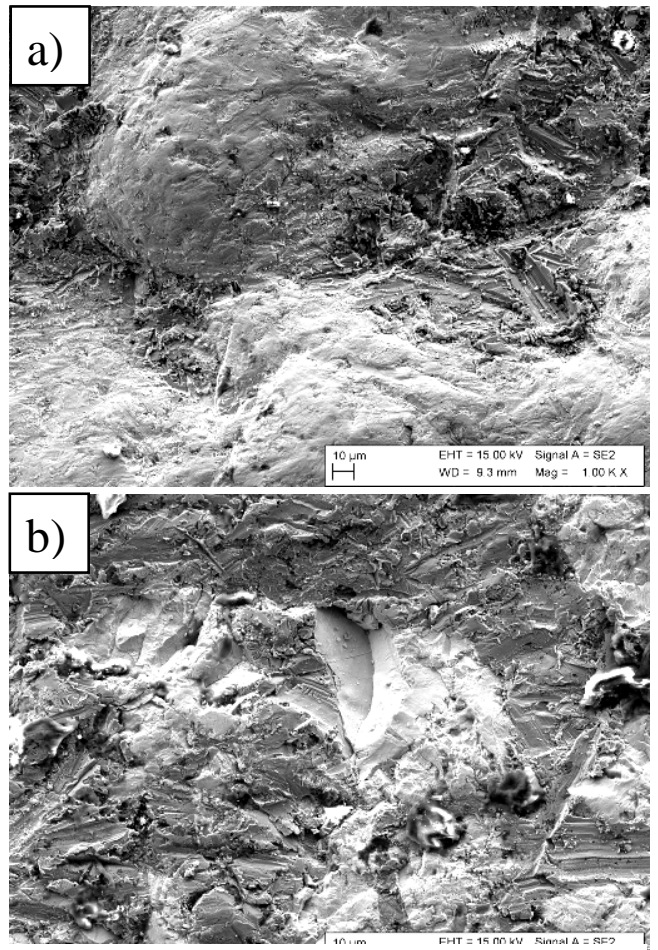

Figure 4. Surface of F50 (a) and MC50 (b) after high stress abrasion carbide used in

crystalline F50 is only about $75 \%$ of the abrading particles. For F50 and FSP50 the corresponding values are $110 \%$ and $120 \%$ respectively.

Studying the worn surface on F50MC from high stress abrasion testing (figure 5) it becomes clearer why it performs slightly worse than the others. The carbides in the F50MC material exhibit more fracturing compared to the fused carbides, that show very little signs of fracturing. In F50 the wear is dominated by rounding of the carbide particles followed by a gradual material removal (figure 5). There is a marked difference in topography in the wear scar comparing the materials. In the material containing the harder fused carbides the carbides protrude from the surface, a clear indication that they quite effective resisting the wear from the $\mathrm{Al}_{2} \mathrm{O}_{3}$ particles. The topography in the wear scar for F50MC material is much smoother and contains more debris in the form of carbide fragments but also $\mathrm{Al}_{2} \mathrm{O}_{3}$ particles.

In scratch testing the MC carbide again displays a 
tendency to crack more compared to the fused carbides, see figure 6. Even though the MC carbide has a lower dissolution most of the positive effect gained from this is lost due to the susceptibility to cracking as well as a lower hardness.

The fused carbide exhibit significant damage on the edges where carbide dissolution has formed a structure that readily deforms and cracks i.e. it increases the mean free path between the more solid core of the primary carbides. Comparing this to the results in abrasion testing, it is apparent that this dissolution accelerates the wear in the matrix as well as the dissolution zone between matrix and primary carbide.

The worn surfaces from lab testing have been compared to worn surfaces of parts that have been in service under different operating condition. One where much of the wear is closer to low stress abrasion (pump part) and one that is subjected to high stress abrasion and impacts (crusher tooth). Both parts are using a wear material that is similar to F50 but have an optimized matrix composition. There are some clear similarities to the lab scale testing when studying the worn surfaces. For the crusher tooth the worn surface is quite flat with lots of fractured carbides (figure 7 a), quite like what was observed in the high stress abrasion testing. The depth in to the material to which the carbides are fractured is surprisingly low for it being an application with impacts wear also, only about $0,5 \mathrm{~mm}$.

Studying the worn surface of the pump part instead (figure $7 \mathrm{~b}$ ) the similarity to the worn surface from the low stress abrasion test is significant. The carbides stand proud from the surface and the matrix between them is worn away. Unlike the surface from lab testing the surface contain some carbide damage like abrasion, cracking and micro chipping, although to a quite low extent.
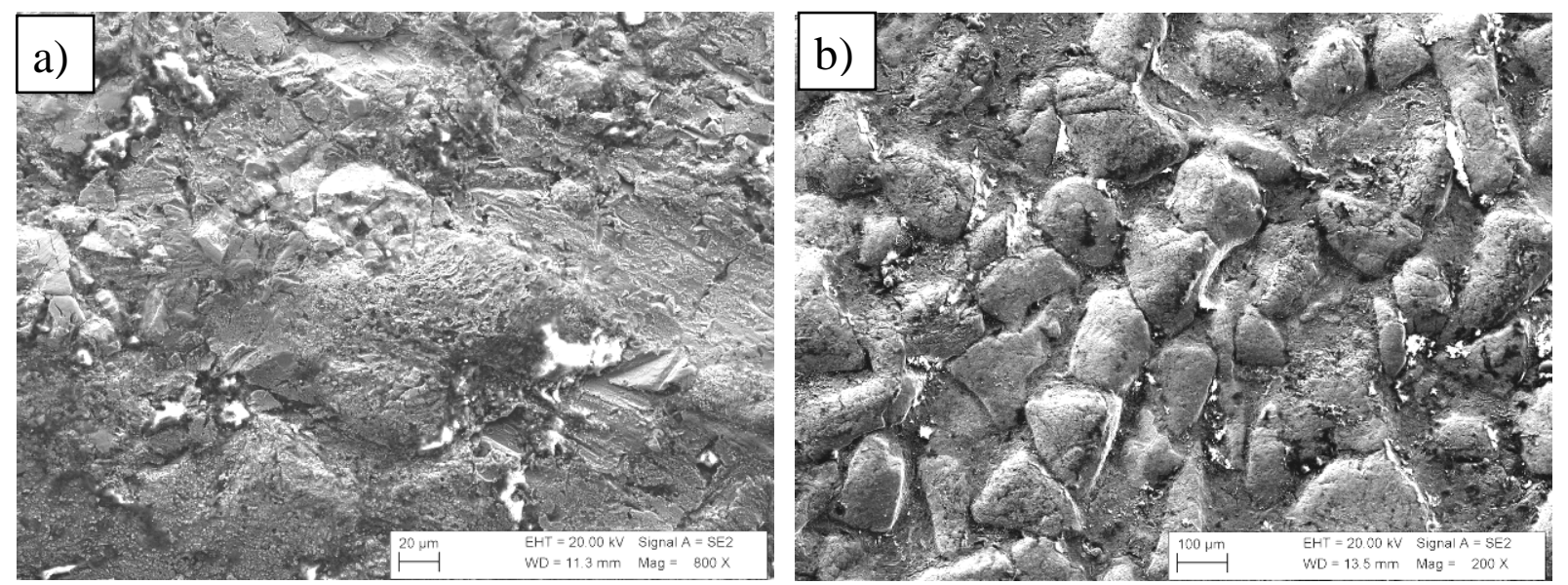

Fiaure 6. Worn surface of crusher tooth (a) and numn side liner (b).

\section{Conclusions}

- Angular fused tungsten carbide exhibit a higher degree of carbide dissolution compared to spherical fused carbide when HIPed at the same conditions

- Macrocrystalline carbide exhibits lowest degree of carbide dissolution compared to both of the fused carbides

- Lower carbide dissolution result in better wear resistance in the early stages of wear during low stress abrasion testing

- There is a good correlation between carbide hardness and wear resistance in high stress abrasion testing

- Higher degree of carbide dissolution increases the hardness of the matrix 
- The wear mechanism in the pump part is similar to low stress abrasion

- The wear mechanism in the crusher tooth is similar to high stress abrasion

\section{References}

[1] Y.Pan, D. Y. Li and H. Zhang, Wear 271 (2011) 1916-19-21.

[2] H. Berns, Wear 254 (2003) 47-54.

[3] S. Bodhak, B. Basu, T. Venkateswaran, W. Jo, K.-H. Jung and D.-Y. Kim, J. Am. Ceram. Soc. 89[5] (2006) 1639-1651.

[4] R. M. Genga, G. Akdogan, J.E. Westraadt and L.A. Cornish, Int. J. Refract. Met. Hard Mater. 49 (2015) 240-248.

[5] R. M. Genga, G. Akdogan, C. Polese, J.C. Garrett and L.A. Cornish, Int. J. Refract. Met. Hard Mater. ARTICLE IN PRESS (2014).

[6] S. Olovsjö, R. Johanson, F. Falsafi, U. Bexell and M. Olsson, Wear 302 (2013) 1546-1554.

[7] Seger. R, Effect of tungsten carbides properties of overlay welded WC/NiSiB composite coatings, Thesis work, 2013, Höganäs

[8] T. Liyanagea, G. Fisher, A.P. Gerlicha, Wear 274-275 (2012) 345-354

[9] M. Jones, U. Waag, Wear 271 (2011) 1314-1324

[10] S. Wirojanupatump, P.H. Shipway, Wear 239 (2000) 90-101

[11] Jacobson, Staffan \& Hogmark, Sture (1996). Tribologi: friktion, smorjning och nötning. 1. utg. Stockholm: Liber utbildning 